\title{
ОБЗОР И АНАЛИЗ МЕЖДУНАРОДНЫХ НОРМАТИВНЫХ ДОКУМЕНТОВ, ОПРЕДЕЛЯЮЩИХ УРОВЕНЬ БЕЗОПАСНОСТИ И КАЧЕСТВА ПИТЬЕВОЙ ВОДЫ
}

Конык А.В., канд. техн. наук

\section{Институт технической теплофизики НАН Украины, ул. Желябова, 2а, г. Київ, 03680, Украина}

У статті приведено аналіз Статья содержит анализ дейдіючих у світі нормативних ствующих нормативных документов, документів, що регламентують которые регламентируют качество и якість і безпеку питної води. Пред- безопасность питьевой воды. Приставлено порівняльну таблицю ведена сравнительная таблица фифізико-хімічних, радіологічних, мік- зико-химических, радиологических, робіологічних та органолептичних микробиологических и органолеппараметрів води, що містить тических параметров воды, которая відомості про гранично допустимі содержит информацию о предельно концентрації небезпечних речовин. допустимой концентрации опасных веществ.

To the article the analysis of operating in the world normative documents that regulate quality and safety of drinking-water is driven. The comparative table of physical and chemical, radiological, microbiological parameters and taste, smell properties of water that contains information about the maximum possible concentrations of hazardous substances is presented.

Библ. 8, табл. 1.

Ключевые слова: международные нормативные документы, физико-химические и микробиологические параметры, органолептические свойства, вода.

БОЕ - число бляшко-образующих единиц;

ВОЗ - Всемирная Организация Здравоохранения; ДИВЭ - дискретно-импульсный ввод энергии; ЕМФ - единица мутности по фармазину; ЕС - Европейское Сообщество; СанПиН - санитарные правила и нормы; ПДК - предельно допустимой концентрации;

Важность и роль воды в жизни каждого человека не вызывает сомнений. Значение воды для промышленности переоценить сложно, она используется как технологическое сырьё для обеспечения технологического процесса и как компонент для приготовления получаемого продукта. Основное значение имеют её физико-химические свойства, химический состав, $\mathrm{pH}$, органолептические и микробиологические параметры, температура, проводимость, стабильность воды и другие не менее важные показатели. Но качество и безопасность воды потребляемой человеком не должны негативно влиять на здоровье и состояние организма в целом. Поэтому физико-химичес-
ПСП - переносимое суточное потребление;

MAC - максимально допустимая концентрация;

MCLG - максимальный уровень загрязняющих веществ;

$\mathrm{MCL}$ - максимально допустимый уровень загряз нения;

USEAP - Агентство по охране окружающей среды Соединенных Штатов Америки.

кие, микробиологические, токсикологические и радиационные свойства воды предназначенной для нужд населения и промышленности нормируются согласно документам, которые более подробно будут рассмотрены далее.

Мировое сообщество для обеспечения безопасности воды, предназначенной для потребления населением, использует международные рекомендации Всемирной Организации Здравоохранения «Руководство по контролю качества питьевой воды». Этот документ является основополагающим, на основании рекомендаций которого разрабатываются нормирующие документы других государств. Для стран ЕС эти нормы опре- 
деляются директивой Европейского Сообщества - «По качеству питьевой воды, предназначенной для потребления человеком» 98/83/EC, на территории США действуют нормы Агентства по охране окружающей среды. Качество воды в пределах Российской Федерации определяет СанПиН 2.1.4.559-96 "Питьевая вода. Гигиенические требования к качеству воды централизованных систем питьевого водоснабжения. Контроль качества". Эти документы призваны обеспечить качество питьевой воды, т.е. её безопасность [1-7], рассмотрим особенности и подходы к решению этого вопроса.

Основная функция Всемирной Организации Здравоохранения (World Health Organization) cocтоит в решении международных проблем здравоохранения и охраны здоровья населения. В 1984 году этой организацией было издано "Руководство по контролю качества питьевой воды", пересмотренное и дополненное в 1992 году. Рекомендации ВО3 явиляются результатом многолетних фундаментальных исследований. Основным критерием оценки качества воды является показатель - переносимого суточного потребления. Данное понятие определяется соотношением количества вещества (поступающее в организм с пищей, водой, и др.) на массу тела человека (мг/кг или мкг/кг), которое может ежедневно потребляться на протяжении жизни без заметного риска для здоровья. В результате исследований установлены значения ПСП по основным потенциально вредным для человека веществам. На основании этих данных с применением сложной системы поправочных коэффициентов были разработаны нормы содержания основных вредных веществ в воде. При определении численных значений рекомендуемых величин для воды учитывалось поступление вещества из всех источников (с пищей, дыханием и т.п.), это гарантирует, что суммарное суточное потребление вещества из всех источников (включая питьевую воду, содержащую концентрацию этого вещества на уровне, равном или близком рекомендованной величине) не превысит переносимого суточного потребления $[2,4,5]$. Предложение ВО3 по содержанию загрязняющих веществ в воде приведено как связка параметров: рекомендации ВОЗ по безвредной для человека концентрации веществ в питьевой воде, допустимое поступление химических веществ в организм человека и сведения о токсичности соединений химических веществ для животных и человека, в таблицу внесены значения рекомендаций, как несущие определяющий характер.

Директива Европейского Сообщества (European Community) 80/778/EC была принята Европейским Советом 15 июля 1980 года, известна под названием "Директива по Питьевой Воде" (Drinking Water Directive). Данный документ, касающийся качества воды, предназначенной для потребления населением, стал основанием для законодательства водного хозяйства европейских стран-членов ЕС. В директиве для большинства параметров установлено два уровня предельно допустимой концентрации: уровень $\mathrm{G}$ - это долговременная цель, которую странам-членам ЕС желательно достигнуть в перспективе; уровень I - это обязательный для выполнения всеми странами порядок величин, определяющих качество воды.

В Директиве эти нормы закреплены в виде величин MAC (Maximum Admissible Concentration) для каждого параметра. Законодательство стран-членов ЕС должно устанавливать нормы качества воды не выше, чем величина МАC.

С 3 ноября 1998 г. Советом Европейского Союза взамен действовавшей с 1980 г была принята директива "По качеству питьевой воды, предназначенной для потребления человеком" 98/83/ЕС. В новом издании директивы перечень обязательных для контроля параметров сокращен, но предельные значения по многим из них ужесточены. В Директиве ЕС нормируются параметры качества питьевой воды, которые разделены на несколько групп: органолептические показатели, физико-химические параметры, вещества, присутствие которых в воде в больших количествах нежелательно, токсичные вещества, микробиологические показатели и параметры умягченной воды, предназначенной для потребления $[1,3]$. В директиве 98/83/ЕС в приложении I части А и В содержат химические и микробиологические параметры и параметрические величины носящие обязательный характер, в части C содержатся индикаторные параметры для 
мониторинга состояния воды. В сравнительную таблицу внесены значения как обязательные, так и индикаторные величины.

В Соединенных штатах Америки вопросы безопасности и качества воды входит в компетенцию Агентства по охране окружающей среды США (United State Environment Protection Agency). Это правительственное учреждение, в обязанности которого входит защита здоровья населения и охрана окружающей среды. Агентством был разработан федеральный стандарт определяющий качество питьевой воды США, который включает два раздела:

- обязательный для соблюдения, объединяющий на сегодняшний день 79 параметров (органические и неорганические примеси, радионуклиды, микроорганизмы), потенциально опасных для здоровья человека - National Primary Drinking Water Regulations;

- рекомендационный стандарт, включает 15 параметров, превышение нормативов по которым может ухудшить потребительские качества воды - National Secondary Drinking Water Regulations.

C 1986 года по каждому параметру установлены два норматива Maximum Contaminant Level Goal (MCLG) и Maximum Contaminant Level (MCL). MCL - это обязательная для соблюдения величина, представляющая собой предельно допустимый уровень по каждому параметру качества воды. Данная величина устанавливается максимально близко к MCLG с учетом современных технологических возможностей и экономической целесообразности. MCLG - представляет собой тот максимальный уровень, при котором данное вещество (воздействие) гарантированно не оказывает вредного влияния на организм человека. Строгое соблюдение этого уровня не является обязательным, но является желаемым, к которому следует стремиться. По большинству позиций величины MCLG и MCL совпадают, однако у ряда параметров (канцерогены, микробиология, радионуклиды) величина MCLG значительно жестче и, как правило, равна нулю, что означает стремление к достижению полного отсутствия данного вида загрязнений $[2,4,6]$.

На территории Российской Федерации действуют санитарные правила и нормы РФ СанПиН 2.1.4.559-96 "Питьевая вода. Гигиенические требования к качеству воды централизованных систем питьевого водоснабжения. Контроль качества" утвержден постановлением Госкомсанэпиднадзора РФ от 24.10.1996 г. и введен в действие с 1 июля 1997 года. Документ разработан на основании данных российских ученых с учетом рекомендаций ВОЗ. СанПиН 2.1.4.559-96 устанавливает гигиенические требования к питьевой воде, нормирует содержание вредных химических веществ, наиболее часто встречающихся в природных водах, а также поступающих в источники водоснабжения в результате хозяйственной деятельности человека, определяет органолептические и некоторые физико-химические параметры питьевой воды.

Отличительной чертой этого документа является наличие, кроме предельно-допустимой концентрации вещества, дополнительных значений показателя вредности и класса опасности. Дополнительно введены понятия показателя вредности и класса безопасности.

Показатель вредности - это лимитирующий признак вредности веществ, по которому установлен норматив. Класс опасности - это показатель, характеризующий степень опасности для человека веществ, загрязняющих питьевую воду. Согласно градации вещества делятся на следующие классы опасности: 1 класс - чрезвычайно опасные; 2 класс - высокоопасные; 3 класс опасные; 4 класс - умеренно опасные. Учитывать класс опасности загрязняющих веществ крайне важно, так как они могут обладать кумулятивном эффектом. Это означает, что несколько особо вредных веществ, даже если содержание каждого из них не превышает предельно допустимой концентрации, могут в совокупности сделать воду опасной. То есть вода, формально удовлетворяющая нормам по всем отдельным параметрам, в целом может оказаться не пригодной для питья. Поэтому при обнаружении в питьевой воде нескольких химических веществ, относящихся к 1 и 2 классам опасности и нормируемых по санитарно-токсикологическому признаку вредности, определяют сумму отношений фактических концентраций каждого из них к величине его ПДК. Эта сумма не должна превышать 1 [2,3,7].

Вода для потребления населением Украины нормируется «Державними санітарними нор- 
мами та правилами «Гігієнічні вимоги до води питної, призначеної для споживання людиною»»» ДсанПіН 2.2.4-171-10, а также разработан обобщающий документ ДСТУ «Вода питна. Вимоги та методи контролю якості», который распространяется на воду питьевую централизованного и нецентрализованного водоснабжения. Основу документа составляют 82 действующих нормативных акта, которые регламентируют 80 параметров воды. Параметры условно разделенных на 10 групп: микробиологические параметры, вирусологическая безопасность, паразитологическиие показатели, микологический показатель, уровень токсикологической безопасности, показатели радиационной безопасности, органолептика и химические показатели влияющие на органолептические свойства воды, токсикологические показатели безопасности химического состава (20 - неорганических компонентов, 6 - органических компонентов и 2 интегральные показатели) и вещества, которые образовываются в процессе водоподготовки. В разработанном документе учтены рекомендации ВОЗ.

Основной действующий документ, нормирующий химические параметры питьевой воды ДсанПіН 2.2.4-171-10 «Гігієнічні вимоги до води питної, призначеної для споживання людиною», регламентирует определение ряда важнейших параметров, а также нормирует показатели: микробиологической безопасности, паразитологической безопасности, органолептические показатели, физико-химические характеристики, санитарно-токсикологические показатели [5]. Значения этих параметров приведены в сравнительной таблице 1 в соответствующей графе. Необходимо отметить, что по большинству параметров ДсанПіН 2.2.4-171-10 «Гігієнічні вимоги до води питної, призначеної для споживання людиною», удовлетворяет рекомендациям ВОЗ. В сравнительной таблице 1 приведены ключевые параметры, определяющие безопасность и качество воды действующих нормирующих документов.

Необходимо отметить, что в зависимости от комплексности проблем присущих водным ре- сурсам определённого континентального региона рассматриваются соответствующие параметры безопасности воды. Так, например, для стран Евросоюза, где ресурсы внутренних бассейнов весьма ограничены, но развита промышленность, особое внимание требуют параметры органических показателей и микробиологии. Проблемы экологического характера водных ресурсов Украины и Российской Федерации нашли отображение в расширенном спектре радиологических параметров и показателей органической химии.

В Институте технической теплофизики НАН Украины в рамках научного направления дискретно-импульсного ввода энергии проведены исследования влияния механизмов ДИВЭ на физико-химические и микробиологические показатели воды и водных систем [8]. Основные механизмы ДИВЭ, которые использовались в исследованиях - это эффекты, связанные с ускорением движения непрерывной фазы; кавитационные механизмы вызванные мгновенным сбросом давления $\frac{d P}{d \tau}=1,5 \frac{\Gamma П а}{\mathrm{c}}$; адиабатическое закипание; коллективные эффекты в ансамбле пузырей; турбулизация межфазной поверхности паро-жидкости пузырьковых сред. Установлено, что в результате обработки происходит снижение: общей жёсткости до 35,2 \%; общей щёлочности до 27,4 \%; окисление перманганата до 35, 5 \%; количества сухого остатка до 12,4 ; массовой концентрации железа до 37,5 \%; фтора до $21 \%$; аммиака и ионов аммония до $60 \%$. Происходит повышение водородного показателя до 20 \%, наблюдается снижение электропроводности до 14,6 \%. Также отмечается улучшение микробиологических параметров по показателям общего микробного числа и индекса группы бактерий кишечной палочки. Результаты экспериментальных исследований (таблица 1) были сопоставлены с соответствующими показателями нормирующих документов, а именно с ДсанПіН 2.2.4-171-10 «Гігієнічні вимоги до води питної, призначеної для споживання людиною», и установлено их согласование по основным физико-химическим и микробиологическим показателям. 


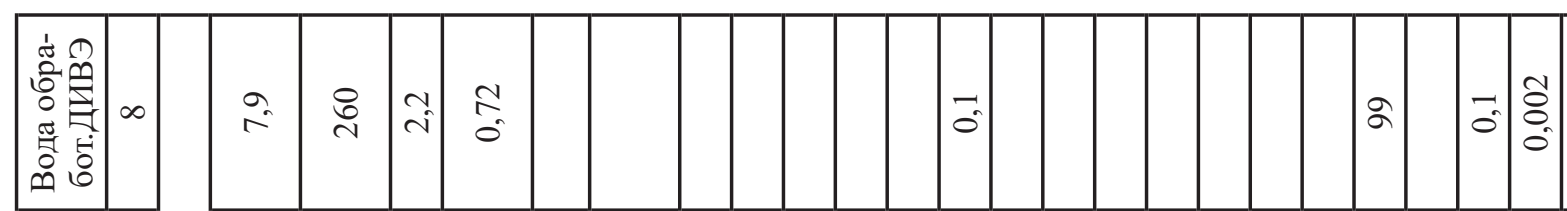

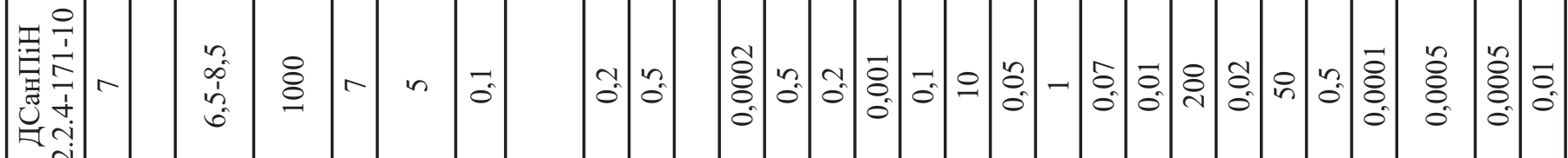

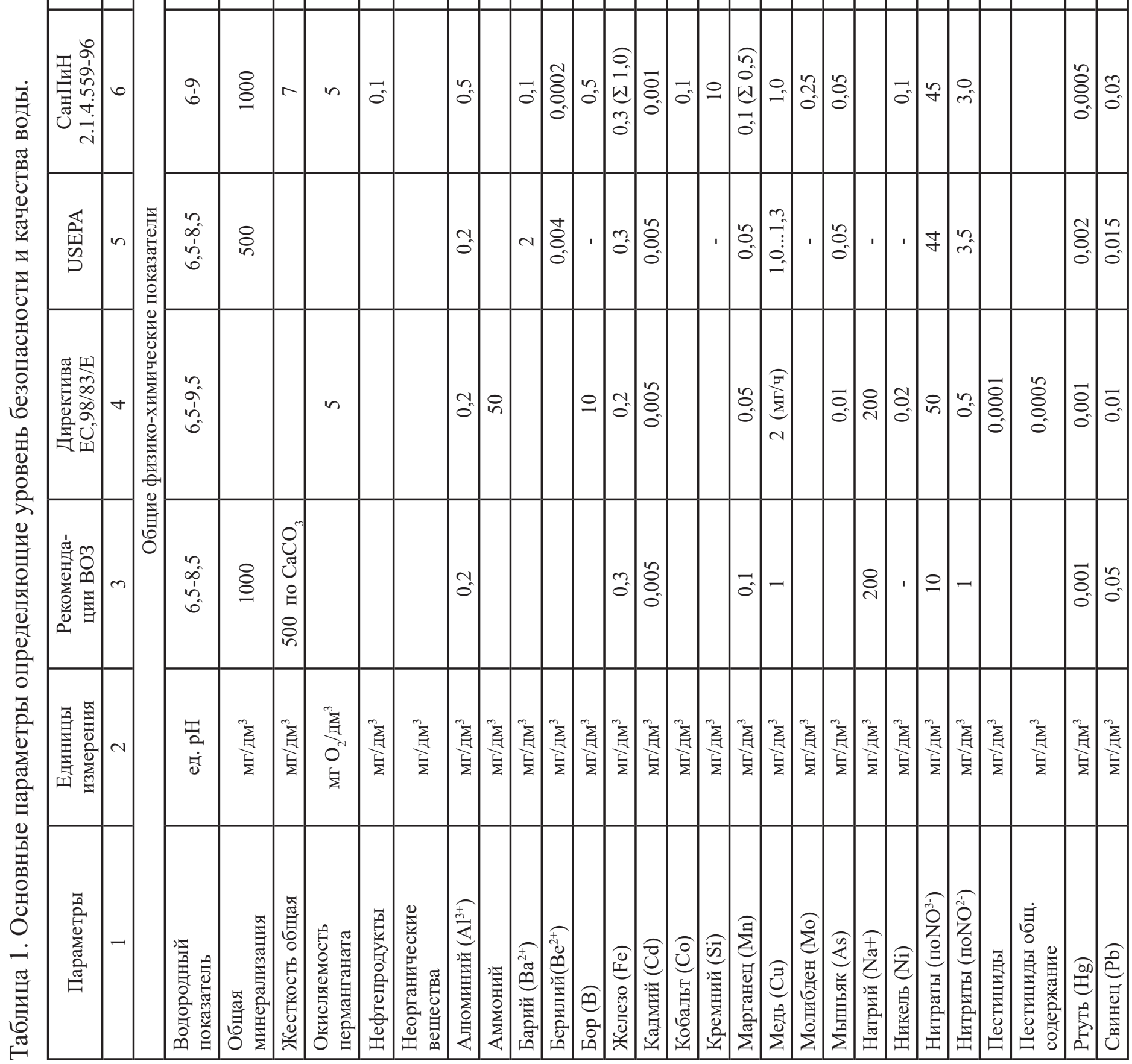




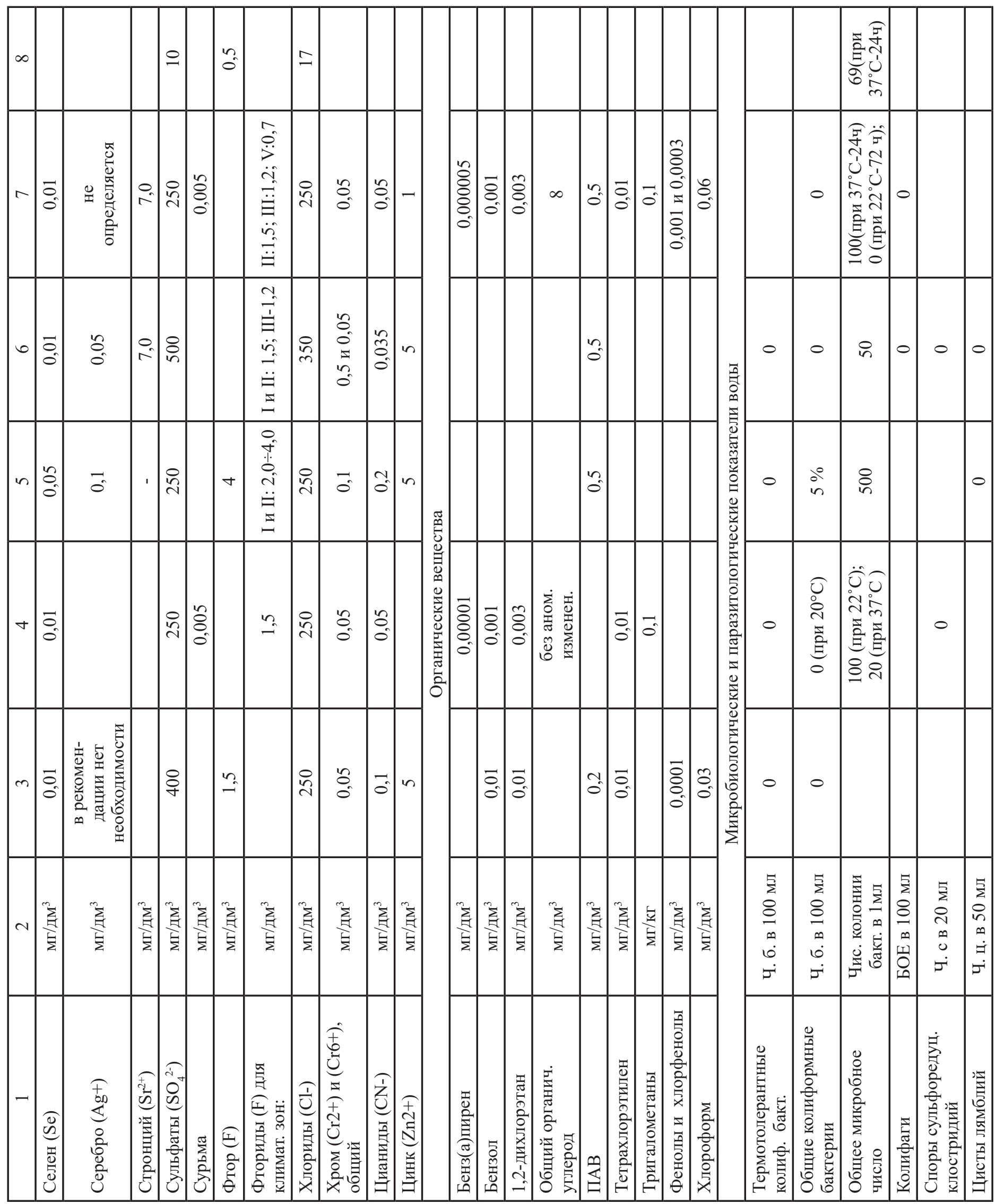




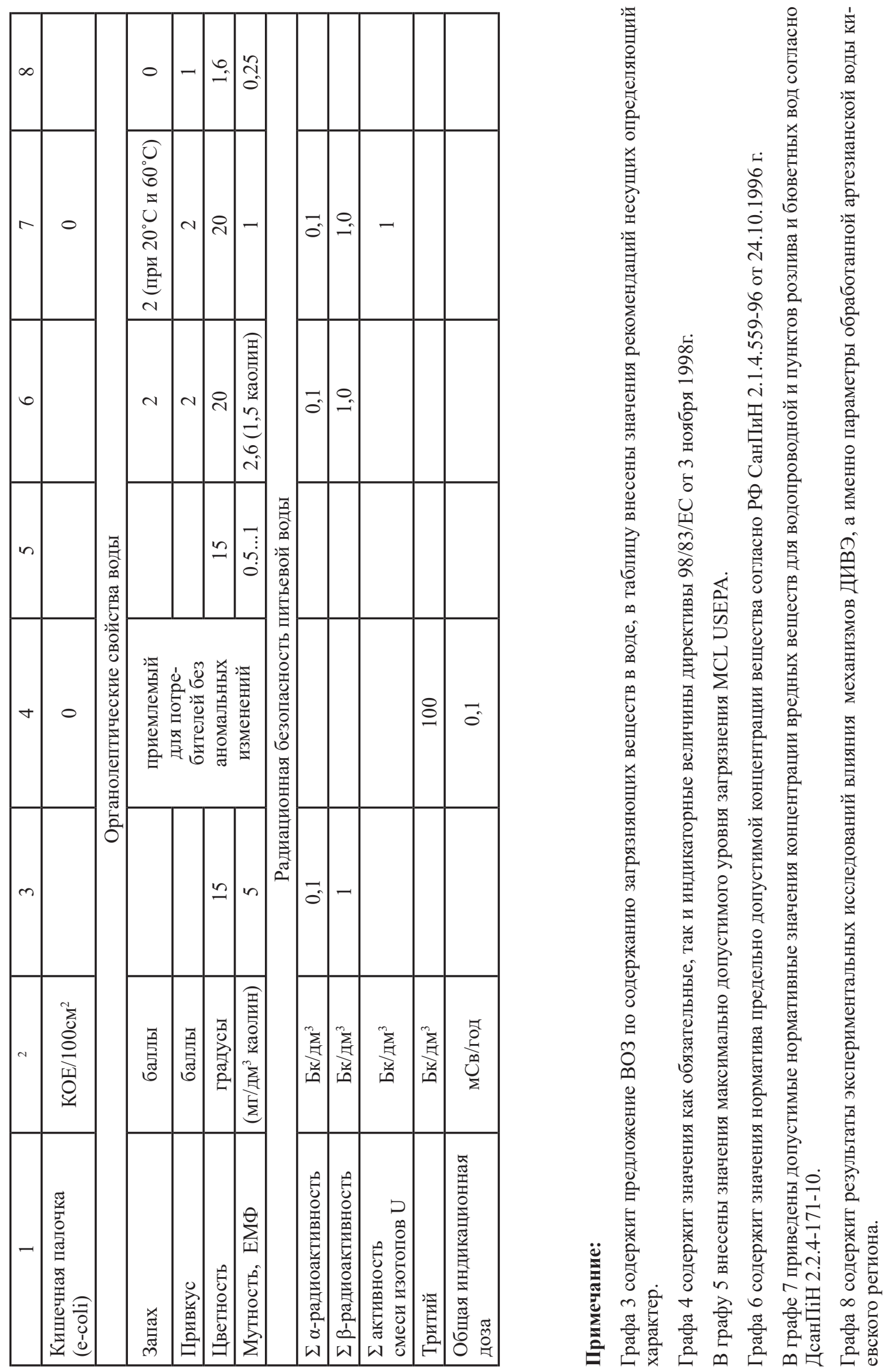




\section{Выводы}

По результатам анализа действующих нормативных документов, которые регламентируют безопасность и качество воды предназначенной для потребления населением следует отметить комплексность и обобщённость подходов к решению поставленных задач. Рассмотренные нормирующие документы независимо от подхода к определению допустимого уровня концентрации вредных веществ, согласуются между собой и условно объединяются в несколько групп: общие показатели, неорганические и органические вещества, микробиологические и паразитологические показатели, органолептические свойства и радиационная безопасность. Проверка основных параметров воды обработанной методом дискретно-импульсного ввода энергии показала соответствие действующим нормативным документам.

\section{ЛИТЕРАТУРА}

1. Директива 98/83/ЕС Совета от 3 ноября 1998 года, о качестве воды, предназначенной для употребления людьми / http://old.aquaexpert.ru/ analytics $/ ? \mathrm{id}=21 \& \mathrm{t}=2$

2. Нормы качества питьевой воды. ГОСТ 2874-82 (отменен), СанПиН 2.1.4.10749-01 "Питьевая вода. Гигиенические требования к качеству воды.", ЕС - директива 98/83/ЕС "По качеству питьевой воды, предназначенной для потребления человеком", международные рекомендации ВО3 "Руководство по контролю качества питьевой воды 1992 г.", нормы Агенства по охране окружающей среды США http:// www.dpva.info/Guide/GuideTechnologyDrawings/ WaterSupply WasteWater/Drinking Water/ DrinkWater

3. Рябчиков Б.Е. Современные методы подготовки воды для промышленного и бытового использования / Рябчиков Б.Е. - М.: ДеЛи принт, 2004. -328 c.

4. Качество водыл. Стандарты и нормы http:// akvant.com.ua/st/10.php

5. Державні санітарні норми та правила «Гігієнічні вимоги до води питної, призначеної для споживання людиною» (ДСанПіН 2.2.4-17110). C. 47

6. Качество воды http://talavoda.kiev.ua/ quality-awards.html

7. Государственный стандарт на питьевую воду. http://voda-resurs.ru/?p=150

8. Сланік А.B. Використкання механізмів дискретно-імпульсного введення енергії для обробки води. Дис. на здобуття ступ. к.т.н. - 190 с. 


\section{REVIEW AND ANALYSIS OF INTERNATIONAL NORMATIVE DOCUMENTS, QUALIFICATORY STRENGTH AND QUALITY OF DRINKING-WATER SECURITY}

\section{Konyk A.V.}

Institute of Engineering Thermophysics of the National Academy of Sciences of Ukraine, vul. Zhelyabova, 2a, Kyiv, 03680, Ukraine

To the article the analysis of operating in the world normative documents that regulate quality and safety of drinking-water is driven. The comparative table of physical and chemical, radiological, microbiological parameters and taste, smell properties of water that contains information about the maximum possible concentrations of hazardous substances is presented. In detail going is considered near determination of safe level of concentration of harmful substances. References 8, table 1 .

Key words: international normative documents, physical and chemical and microbiological parameters, taste and smell properties, water.

1 Directive 98/83 / EU council from 3 November 1998 about quality of water, appointment for use of human / http://old.aquaexpert.ru/ analytics $/$ ? $i d=21 \& t=2$. (Rus.)
2. Drinking water quality standards. State standard 2874-82 (canceled), Sanitary rules and norms 2.1.4.10749-01 "Drinking water. Hygienic requirements for water quality.", EU - directive 98/83/EU "About quality of water for human consumption", international recommendations World Health Organization "The guidelines for drinking water quality 1992" Standards of the US Environmental Protection" http://www. dpva.info/Guide/GuideTechnologyDrawings/ WaterSupplyWasteWater/DrinkingWater/ DrinkWater/ (Rus.)

3. Ryabchykov B.E. Advanced methods of water for industrial and civil use. M.: DeLy print. - 2004. -328 p. (Rus.)

4. Water quality. Standards and norms. http:// akvant.com.ua/st/10.php (Rus.)

5. Public health standards and regulations «Hygienic requirements for drinking water for human consumption» (Sanitary rules and norms 2.2.4-171-10). 47 p. (Ukr.)

6. Quality of water http://talavoda.kiev.ua/ quality-awards.html (Rus.)

7. State standard for drinking water. http://vodaresurs.ru/?p=150 (Rus.)

8. Slanik A.V. The use mechanisms of discrete pulse introduction energy for water treatment. Dissertation to get candidate of technical sciences 190 p. (Ukr.) 